\title{
Health worker text messaging for blended learning, peer support, and mentoring in pediatric and adolescent HIV/AIDS care: a case study in Zimbabwe
}

V. Bertman ${ }^{1 *}$ (D, F. Petracca ${ }^{1}$, B. Makunike-Chikwinya ${ }^{1}$, A. Jonga ${ }^{1}$, B. Dupwa ${ }^{2}$, N. Jenami ${ }^{1}$, A. Nartker ${ }^{3}$, L. Wall ${ }^{3}$, L. Reason ${ }^{1}$, P. Kundhlande ${ }^{1}$ and A. Downer ${ }^{1}$

\begin{abstract}
Background: In sub-Saharan Africa, shortages of trained healthcare workers and limited resources necessitate innovative and cost-effective approaches for training, supervising, and mentoring. This qualitative case study describes participants' and trainers' perspectives and experiences with a text messaging component of a blended training course in HIV counseling and testing in Zimbabwe, using minimal resources in terms of staff time and equipment requirements. This component included a whole-group discussion forum as well as two-person partner discussions designed to promote reflection and analysis, teamwork, and active learning.

Case presentation: The Ministry of Health and Child Care (MoHCC) of Zimbabwe collaborated with the International Training and Education Center for Health (I-TECH) on adaptation of a 5-day in-service training in HIV Testing Services for Children and Adolescents. The new 7-week blended format included in-person sessions, tabletbased self-study, and discussions using the text messaging application, WhatsApp. Between August 2016 and January 2017, 11 cohorts (293 participants in total) were trained with this new curriculum, incorporating text messaging to support peer-to-peer and work-based education.

Data collected included training participants' feedback, key informant interviews with the training team, and thematic analysis of WhatsApp messages from full-cohort discussions and a sampling of one-to-one partner discussions.

A total of 293 healthcare workers from 233 health facilities across all provinces in Zimbabwe completed the blended learning course. Participants strongly endorsed using WhatsApp groups as part of the training. In the whole-group discussions, the combined cohorts generated over 6300 text messages. Several categories of communication emerged in analysis of group discussions: (1) participants' case experiences and questions; (2) feedback and recommendations for work issues raised; (3) inquiries, comments, and responses about course assignments and specific course content; (4) encouragement; and (5) technical challenges encountered using the blended learning methodology. Case discussions were complex, including patient history, symptoms, medications, and psychosocial issues — child abuse, adherence, and disclosure.
\end{abstract}

Conclusions: Using text messaging in a communication platform that is an ongoing part of healthcare workers' daily lives can be an effective adjunct to in-service training, minimizing isolation and providing interactivity, supporting students' ability to fully integrate content into new skill attainment.

Keywords: E-learning, Text messaging, SMS, WhatsApp, HIV/AIDS, Blended learning, Healthcare worker training

\footnotetext{
* Correspondence: vbertman@uw.edu

${ }^{1}$ International Training and Education Center for Health (I-TECH), Department

of Global Health, University of Washington, Seattle, WA, USA

Full list of author information is available at the end of the article
}

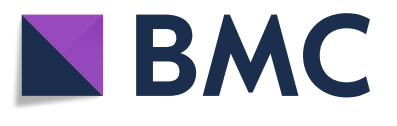

(c) The Author(s). 2019 Open Access This article is distributed under the terms of the Creative Commons Attribution 4.0 International License (http://creativecommons.org/licenses/by/4.0/), which permits unrestricted use, distribution, and reproduction in any medium, provided you give appropriate credit to the original author(s) and the source, provide a link to the Creative Commons license, and indicate if changes were made. The Creative Commons Public Domain Dedication waiver (http://creativecommons.org/publicdomain/zero/1.0/) applies to the data made available in this article, unless otherwise stated. 


\section{Introduction}

A critical shortage of trained health workers impacts the ability of many countries in sub-Saharan Africa to reach UNAIDS global HIV/AIDS targets by 2020-to diagnose 90\% of all HIV-positive persons, provide antiretroviral therapy (ART) for $90 \%$ of those diagnosed, and achieve viral suppression for $90 \%$ of those treated (the "90-90-90" targets). The burden of HIV and health worker shortage has led to the practice of task shiftingdelegation of medical and health service responsibilities from higher to lower cadres of health staff, in some cases non-professionals [1]. To address the HIV epidemic in Zimbabwe, the Ministry of Health and Child Care (MoHCC) has undertaken strategies that include prevention, treatment, care, and support services.

In countries with limited resources, including Zimbabwe, addressing health worker shortages and service needs necessitate innovative, cost-effective approaches for training, supervising, and mentoring healthcare workers. These approaches need to minimize the burden on an already-overwhelmed healthcare system by limiting the time health providers spend away from work posts to attend training, while still providing the instructional experiences that trainees need to perform their jobs well [2]. This report describes one component of a blended instructional approach, using text messaging to support a self-study training for counselors in HIV counseling and testing.

Blended learning combines a variety of learning methods (such as in-person, online, print, and social media) and learning environments (such as instructor-led, teamwork, peer-to-peer, self-study, and individual work) $[3,4]$. Growing evidence supports the effectiveness of the blended learning approach for health worker training and suggests that it is well received and may be a more affordable instructional method when compared with standard classroom instruction [5-8].

Data suggest that students benefit from an environment where a mixture of classroom and online technologies is employed, promoting ongoing interest in the subject matter. Applied and interactive learning have been found to be critical for effective clinical training, so it is important to assure that these aspects of training are not lost in the development of blended learning courses. As Joynes [3] has stated in a systematic review of distance and blended learning training for healthcare workers, "...methods that actively involved learners interacting with learners in a clinical environment were theoretically and empirically superior in their educational effectiveness as compared to either classroom-based activities and/or didactic activities...."

Peer-to-peer interaction through email or online discussion forums increases opportunities for reflection and analysis, supports teamwork, and moves learners from passive to active learning $[9,10]$. Training programs that include significant components of work-based training support learners in attainment of competencies and the application of behavior change due to deeper understanding of content and the opportunity for students to reflect on their own learning and perceptions [3].

One low-cost approach to incorporating interaction into blended learning is through text messaging (also known as "short message service" or SMS). Literature is minimal regarding the use of SMS as an interactive component of blended learning in healthcare worker training, although this modality is increasingly being employed in various contexts, including university coursework [11], health worker supervision [12], military physician mentoring [13], and direct patient support [14]. Suggested benefits of incorporating social media into healthcare worker training include workers' familiarity with this technology, ready access to it, and frequency of use [15], user satisfaction [16], and improved knowledge and confidence [17].

\section{Background}

In Zimbabwe, primary counselors (PCs) are a cadre of health worker that has been established to support task shifting, providing HIV testing and counseling (HTS) to adult, adolescent, and pediatric patients. This cadre of health worker is secondary school educated, a minimum of 25 years of age, and, in general, has no formal medical education prior to being employed as PCs. These health workers are the target audience for a blended learning course in HTS for children and adolescents.

Healthcare worker training in HIV counseling skills for children and adolescents has been identified as a critical component of strengthening efforts towards reaching the 90-90-90 targets [18], as HTS is an entry point to HIV prevention, treatment, care, and support. Zimbabwe's national adult prevalence of HIV is estimated at $14 \%$, with an estimated 33000 new infections annually and a mother-to-child transmission (MTCT) rate of $5.2 \%$. For children and adolescents, the prevalence rate is estimated at $0.9 \%$ for infants aged 0 to 17 months, $0.8 \%$ for those 18 to 59 months, $1.7 \%$ for children 5 to 9 years old, $2.5 \%$ for children 10 to 14 years old, and $3.6 \%$ for adolescents 15 to 19 years of age. Viral suppression is estimated at approximately $50 \%$ for children 5 to 19 years of age [19].

Counseling, care, and support are required by three main groups of children: children who have been confirmed HIV negative, children who have tested HIV negative yet remain HIV exposed or at risk of HIV transmission, and children who have been confirmed HIV positive. Children and adolescents present unique challenges that differ from those of adults, further 
underlying the need for healthcare worker training which specifically targets the counseling and testing of young people. Common counseling issues for children and adolescents may include developmentally diverse physical and psychosocial needs and communication abilities, family challenges and housing instability, abuse, disclosure, legal and ethical issues surrounding age of consent and the principle of best interest of the child; the need to equip children and their caregivers with accurate information about their condition and the implications of living with HIV; and coping with stigma and discrimination $[20,21]$.

\section{Case presentation}

This case study describes a training intervention using WhatsApp, a mobile phone text messaging application that is in widespread use worldwide [22], as one component of a blended learning program. The course was designed to build the skills and knowledge of PCs in HIV-related counseling for children and adolescents. Questions being addressed include the following: Did trainees participate in the text messaging groups and in what ways? What were the perceptions of trainees and trainers on the text messaging component of the training? What lessons could be learned from their experiences to apply to future use of this instructional method?

Zimbabwe's MoHCC developed the HTS for Children and Adolescents guidelines and accompanying in-service training to address the needs and challenges related to identifying HIV-infected youth [23]. In collaboration with MoHCC, The International Training and Education Center for Health (I-TECH) adapted the 5-day in-service training to a 7 -week blended training that included tablet-based self-study, a one-and-a-half-day classroom session at the beginning of the course, and a 4-hour classroom session at the end. The self-study component included videos, podcasts, case studies, quizzes, and self-reflection questions. These activities were complemented by the SMS component, including a whole-group discussion forum as well as two-person partner discussions. The course was facilitated by three trainers who presented content, managed logistics, and interacted with the WhatsApp groups. Staffing did not include an information technology manager; participants were invited to send messages or call one of the trainers if technical issues arose.

Participants were expected to communicate with their partner, using their personal mobile devices and SIM cards, via WhatsApp each week, and the entire class cohort participated in the group WhatsApp discussion. At the end of each week, the pairs were required to forward their discussions to the course facilitator, who awarded course credit based on timeliness, relevance of the case to the week's topic, and responses received from the partner. The course facilitators used WhatsApp to make announcements and send encouragement and reminders about the weekly assignments and to provide feedback and suggestions in response to participants' cases. Participants who completed all assignments and attended the face-to-face sessions were given certificates at the end of the training.

Between August 2016 and January 2017, a total of 11 cohorts were trained with this new curriculum, incorporating WhatsApp to support peer-to-peer and work-based education.

\section{Methodology}

This SMS intervention was one component of a formative assessment of blended learning in Zimbabwe, which aimed to gather information on target audiences, needs, barriers, and facilitators to effectively implementing healthcare worker training using this new and innovative approach. The formative assessment was conducted in collaboration with the Zimbabwe MoHCC and was approved, with a non-research determination, by institutional review boards at the University of Washington, CDC Zimbabwe, CDC Atlanta, and the Medical Research Council of Zimbabwe.

To evaluate the SMS component of the blended learning program, qualitative data were collected from 10 of the 11 cohorts; one group's data was incomplete due to inadequate memory on the device. The data included:

- Participants' feedback provided during debrief discussions with peers $(n=293)$, trainers $(n=2)$, and administrators $(n=1)$, at the final face-to-face classroom sessions between October 2016 and January 2017;

- Key informant interviews conducted in June 2017 with the training team $(n=3)$ who ran the program; and

- Thematic analysis of WhatsApp messages, from fullcohort discussions and a sampling of one-on-one partner discussions.

For all data, no individual identifiers were stored with data to ensure confidentiality of participant information. Verbal consent was obtained from respondents to participate in the study. Key informant interviews were conducted with program trainers. Interviews were recorded and notes were taken. For debrief discussions and interviews, facilitators followed a semi-structured format and used a discussion guide that included questions about participants' experiences with the training modalities, as well as about the training content-what went well, what they learned, and challenges they experienced. Each debrief session was conducted by a facilitator and an 
additional evaluator who took notes on participant responses.

For analysis of the full-cohort and partner discussions, the text messages were extracted from the administrator's device, uploaded in a Microsoft Word file to a password-protected folder, and analyzed using Atlas.ti software. Thematic analysis of all data was conducted by two members of the evaluation team who were blind to the identities of the participants, and analysis followed a general inductive approach [24]. Starting with the primary focus of the evaluation-identifying needs, barriers, and facilitators to using WhatsApp in this context-a first reviewer read all materials and developed a list of themes identified in the material. Next, each theme was reviewed, and sub-themes were identified, with reviewers discussing and reaching consensus on the assignment of thematic codes to the text. Representative quotes were selected for each theme and sub-theme.

The two different types of discussions-group discussions and partner discussions-were coded and analyzed separately. All 10 cohorts' group discussions were analyzed, in addition to a random sample of 20 of the partner discussions.

\section{Results}

A total of 293 healthcare workers from 233 health facilities across all provinces in Zimbabwe completed the blended learning course. Ninety percent of the participants were primary counselors, and $10 \%$ were nurses who serve as supervisors to primary counselors. Sixty-three percent of participants were female.

Analysis focused on the acceptability, needs, barriers, and facilitators of using SMS as an adjunct to the blended training course. Broad themes related to this focus that emerged in the analysis included positive feedback on the acceptability and use of text messaging as an adjunct to the training course, and extensive use of the platforms for information seeking, support, and case discussion.

All quotes presented in this report were not edited for grammar, spelling, or completeness; however, some were edited for brevity and, where text was extracted, it was replaced with ellipses (“...").

\section{Acceptability and use of text messaging as an adjunct to the training course}

Facilitators' post-course debriefing feedback indicated that participants strongly endorsed using WhatsApp groups as part of the training. As one trainer described it, "Most were thrilled." In addition to general feedback that it was helpful, positive comments included perceptions that the WhatsApp discussion groups helped participants identify their own information gaps; that comments about cases shared by other participants provided learning opportunities for everyone; and that the discussion groups provided access to supervisors, trainers and individuals with greater experience.

Feedback from training administrators similarly indicated that the text messaging component was well received by training participants. They reported a perception that participants' messages showed skill improvement over time. For example, one reported, "Knowledge gap in the appropriate application of skills and techniques improved as the course progressed." Comments extracted from the text messaging discussion transcripts echoed these sentiments: "We are learning really, today I was so excited on the way I handled a counselling session of a child ... guys you feel good when you know what you are doing thanks BL HTS Pilot group." And, "Thanks a lot to everyone in this group I've learnt a lot from your discussions."

Course participants were actively involved in both the partner discussions, which were required, and whole-group discussions, which were optional. In the whole-group discussions, the combined 10 cohorts generated over 6300 text messaging entries; many of these discussions continued after the 7-week course was concluded, and all tablets were returned undamaged. Ongoing post-course communications included social interactions and check-ins, as well as users' real-time usage of the platform to discuss workplace issues, cases, questions, advice, and support.

\section{Communication categories within group discussions}

The group discussions were analyzed, and several broad categories of communication emerged. For this evaluation, the following categories were the primary focus of analysis: (1) participants' own case experiences and questions about them; (2) feedback and recommendations for work issues raised; (3) inquiries, comments, and responses about course assignments and specific course content; (4) encouragement; and (5) challenges encountered and recommendations for using the blended learning methodology. In addition, the platform was used for greetings and social contacts. Examples from these categories are presented below.

\section{Participant's workplace cases, feedback, and recommendations}

Participants were required to use the text messaging partner discussions to present challenging work cases relevant to the module topics. Group discussions were open forums where participants had the option of presenting additional workplace challenges, requesting feedback, and asking questions as they desired. Analysis of the data from both types of discussion revealed that participants were able to use WhatsApp to describe cases' complexity, with detail, including aspects of patient 
history, symptoms, medications, and psychosocial issues-such as child abuse, adherence, disclosure, and support systems-and legal and ethical matters.

Participant 1: A girl 16 came at my clinic ... [her grandma] accuses her of having of sleeping with boys ...both parants died she went to her stepmother who came with her at the clinic she was crying they came to the counselling room. i gave her tissues and offered thm seats ... she stopped crying and said she want to be tested to prove her grandma wrong

we discussed about hiv .results outcome she consented to be tested i tested her and her result were negative $\cdots$

Participant 2: You need to discuss about SRH [sexual and reproductive health] issues its important she is sexual active

Participant 3: How about window period,Social welfare Childline,SRH,widen system, dig for more information.Not bad.

Participant 4: Also give her the infomation that she is at risk though her HIV results are negative

Participant 1: Thank you guys for your response

Participant 5: Is she sexually active or they are just suspicious? If sexually active there is need for counseling on SRH issues as stated already

Needs to know dangers of unprotected sex, discuss about family planning methods, screening for STIs, screening for cervical cancer...

Participant 6: I think you need to assess the girl's support system through widening the system nd explore ...then you also need to assess what the girl feels nd then discuss about SRH issues taking note that every individual have unique feelings.

Inquiries, comments, and responses about course assignments and specific course content

Participants used the group discussion forum to ask questions about course content, as in the example below. Often, several participants responded, some corrected others' incorrect responses, and, at times, a facilitator provided correct information when there was confusion.

Participant 1: Guys help me what is perinatal
Participant 2: Death of the infant soon after delivery with 72 hours in Maternity.

Participant 3: Perinatal is not death.its a period immediately before and after birth

Participant 3: Usually between 20-28 weeks of pregnancy to 4_6weeks after birth

Participant 3: Death of an infant within $72 \mathrm{hrs}$ is early neonatal death

\section{Encouragement}

Facilitators offered motivation to participants in addition to using the WhatsApp discussion groups to deliver messages about the course and its requirements. For example:

Facilitator: Thank you for participating in our tablet self study programme. We hope that you will have a good experience with this training and that you will gain new knowledge and skills to use when working with children, families and adolescents. Empowering children and adolescents to take part in their own health care will help play a role in their retention in care. As Archbishop Desmond Tutu said, "Give young people a greater voice. They are the future and they are much wiser than we give them credit for."

Facilitators also provided encouragement and positive feedback in response to participant posts:

Facilitator: for the job well done. Especially use of soldier game. Well done! With your support he will heal.

Participants gave encouragement to each other. In this example, participants provided suggestions while offering positive feedback and encouragement:

Respondent 1: Sounds like a good session to me, well handled. However I think you should have referred to a support group if there are any around or at least try to widen his support system among his peers.

Respondent 2: I acknowledge involving his Headmaster but mind you he is a youth and identifies best with his peers, a friendlier approach like raising awareness might do more good than punishments and disciplining his peers. I hope this helps your case. Good day.

Respondent 2: I should applaud you for taking the first plunge into the Group discussion. Thank you. 
Respondent 3: Job well done, and most importantly refer him to an active support group that wil make him cope and understand he s not the only adolescene on ART [antiretroviral therapy].

Respondent 4: Well done ... you did very well for motivation reassuarring to discuss about disclosure to the school authorities.

\section{Non-work-related content}

In addition to the primary communication categories reviewed, it was also observed that the group forum was used for posting an assortment of non-work-related content, including jokes, stories, ads, religious messages, or articles. Many of them included emoticons as seen in the example that follows:

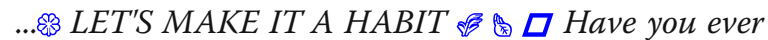
wondered what would happen if we treated the bible the way we treat our 圈 mobile phone...? What if we can carry it with us wherever we go; In our bags 6 .... E our pockets?..

\section{Challenges using SMS as a part of blended learning}

Participant debrief sessions as well as analysis of the message content yielded information about the challenges encountered employing this modality. These included resource issues, including power cuts which made it difficult to recharge the tablets, resulting in delays in adhering to assignment deadlines. In many regions of the country, there is inconsistent mobile phone reception related to the stability of the telecommunications companies. In addition, some participants reported that their phones had limited space for typing case descriptions.

Other challenges reported during the debrief sessions included difficulty balancing work and personal responsibilities with the time needed to complete the course. Some individuals reported frustration that their WhatsApp discussion partners were slow to respond and that they had to turn in their material to the course administrator before the discussion was complete. Technical challenges observed from analysis of the group and partner discussions included a lack of "threading" of case discussions. It was observed that some of the group conversations were broken up, with multiple cases overlapping. At times, this issue resulted in difficulty following a conversation.

\section{Discussion}

The primary questions for this study were the following: Did trainees participate in the text messaging groups and in what ways? What were the perceptions of trainees and trainers on the text messaging component of the training? What lessons could be learned from their experiences to apply to future use of this instructional method? Results suggested that trainees participated actively in the partner and group discussions, describing complex cases, eliciting input from fellow participants, and providing support to each other. The feedback received from trainees and trainers suggested a strong endorsement of this methodology. Analysis of the message content showed that the breadth and complexity of the topics discussed was accommodated using SMS group and partner discussions; participants openly shared and discussed very sensitive case information, while protecting client anonymity. This suggests that participants were comfortable using this platform for peer support, learning, and problem-solving.

The favorable response and wide adoption of use of SMS seen in this case are consistent with findings of a consensus group on in-service training for healthcare workers, in which key priorities for successful instruction included using "accessible learning platforms and mechanisms that can be efficiently updated in a timely manner, in addition to print-based materials." The recommendations of the consensus group also included prioritizing "time efficiency in the design, planning and mode of delivery of training to prevent or minimize health worker absenteeism." Plans for this course incorporated these themes, acknowledging that WhatsApp was a widely used and accessible platform among this cadre [25].

Although research to date is limited on the use of WhatsApp to support training for healthcare workers, some studies have begun to explore this modality. Employing WhatsApp, Goyal et al. [16] found a majority of participants in a pathology residents' WhatsApp discussion in Delhi, India, reported the discussion group was useful. In addition to user satisfaction, some studies indicate positive practice outcomes. Bakshi and Bhawalkar [17] reported positive outcomes of a 3-month WhatsApp discussion group among Korean anesthesia residents, indicating that participants improved in knowledge, confidence, and documentation practices.

The positive results seen in this case study indicate that self-study training using tablets, combined with SMS discussion, may be a useful blended learning approach. Incorporating SMS into the training for partner activities and discussion groups can provide the individual learner with opportunities to minimize isolation [26], provide interactivity, and integrate content into new skill attainment. The SMS component also provides the entire group with peer interaction to enhance and build on the real-life situations they face at work. It is a low-cost platform-one that is accessible, readily used, and has the potential to support the building of healthcare worker knowledge and skills in low-resource settings. 


\section{Limitations}

This was a program evaluation, embedded within an ongoing and evolving program overseen by Zimbabwe's MoHCC. Limitations include the potential for positive response bias: Respondents may have sought to please trainers and evaluators asking for feedback, providing more positive responses than they might otherwise. To minimize this, respondents were reminded of the formative nature of the project and questions and were encouraged to respond honestly. The scope and qualitative case study design of the present study limit generalization to other contexts, as this project focused on one course and one health worker cadre within the context of Zimbabwe's HIV program. This was not an impact study on the effectiveness of the training overall or of the SMS component's contribution to training outcomes; therefore, conclusions drawn from this study are limited to questions regarding use and acceptability of this method.

\section{Conclusions}

The positive results seen in this case study indicate that SMS group and partner discussions were well received and may be valuable components of a blended learning program. In the context of ongoing resource limitations for in-service training, as is seen in Zimbabwe, it is important to support learning experiences for healthcare workers who have complex responsibilities, such as those of the primary counselors participating in this course. Further research may provide additional information about best practices for using SMS as an effective instructional modality in varied settings and for varied training topics, and outcome studies are warranted to yield further evidence to guide program design.

\section{Abbreviations \\ ART: Antiretroviral therapy; HTS: HIV testing and counseling; I- TECH: International Training and Education Center for Health; MoHCC: Ministry of Health and Child Care; MTCT: Mother-to-child transmission; PC: Primary counselor; SMS: Short message service}

\section{Acknowledgements}

The authors are grateful to Stefan Wiktor, Ruth Levine, and Marleyse Borchard for the review and editorial input to the manuscript.

\section{Funding}

This project was supported by Cooperative Agreement Number 1 U2GGH001188-02, funded by the US Centers for Disease Control and Prevention. Its contents are solely the responsibility of the authors and do not necessarily represent the official views of the US Centers for Disease Control and Prevention or the Department of Health and Human Services.

\section{Availability of data and materials}

The data that support the findings of this study are available on request from the Permanent Secretary of the Ministry of Health and Child Care in Zimbabwe and The AIDS and TB program, but restrictions apply to the availability of these data, which were used under license for the current study, and so are not publicly available. Sharing of the data will also require the individual requesting this data to submit a new ethics clearance application with the local ethics review board (Medical Research Council of Zimbabwe) as approval for this study was only granted on the condition that data would not be used for any other purpose other than this study.

\section{Authors' contributions}

NJ, PK, AJ, and VB implemented the intervention. VB and AJ collected participant feedback. VB, LR, and FP analyzed the qualitative data and contributed to the manuscript writing. $A N, L W$, and BD contributed to manuscript writing. $\mathrm{AD}, \mathrm{BM}$, and $\mathrm{BD}$ oversaw the project. All authors provided review and editorial input to the manuscript. All authors read and approved the final manuscript.

\section{Ethics approval and consent to participate}

The assessment was conducted in collaboration with the Zimbabwe MoHCC and was approved, with a non-research determination, by institutional review boards at the University of Washington, CDC Zimbabwe, CDC Atlanta, and the Medical Research Council of Zimbabwe.

\section{Consent for publication}

All authors have approved the manuscript for submission.

\section{Competing interests}

The authors declare that they have no competing interests.

\section{Publisher's Note}

Springer Nature remains neutral with regard to jurisdictional claims in published maps and institutional affiliations.

\section{Author details}

${ }^{1}$ International Training and Education Center for Health (I-TECH), Department of Global Health, University of Washington, Seattle, WA, USA. ${ }^{2}$ Zimbabwe Ministry of Health and Child Care, Harare, Zimbabwe. ${ }^{3}$ Department of Global Health E-learning Program, University of Washington, Seattle, WA, USA.

Received: 22 October 2018 Accepted: 11 April 2019

Published online: 07 June 2019

\section{References}

1. Zachariah R, Ford N, Philips M, Lynch S, Massaquoi M, et al. Task shifting in HIV/AIDS: opportunities, challenges and proposed actions for sub-Saharan Africa. Trans R Soc Trop Med Hyg. 2009;103(6):549-58.

2. Manongi R, Marchant T, Bygbjerg IC. Improving motivation among primary health care workers in Tanzania: a health worker perspective. Hum Resour Health. 2006:4(1):6-12.

3. Joynes, C. Distance Learning for Health: what works. A global review of accredited post- qualification training programmes for health workers in low and middle income countries. London International Development Centre (LDIC). 2011: https://issuu.com/ics_integrare/docs/dl4h_report full Accessed 28 June 2018.

4. Frehywot $\mathrm{S}$, et al. E-learning in medical education in resource constrained low- and middle-income countries. Hum Resour Health. 2013;11:4.

5. Surka $\mathrm{S}$, et al. Evaluating the use of mobile phone technology to enhance cardiovascular disease screening by community health workers. Int J Med Inform. 2014;83:648-54.

6. Feldacker $\mathrm{C}$, et al. Experiences and perceptions of online continuing professional development among clinicians in sub-Saharan Africa. Hum Resour Health. 2017;15:89.

7. Nartker A, Stevens S, Shumays A, Kalowela M, Kisimbo D, Potter K. Increasing health worker capacity through distance learning: a comprehensive review of programmes in Tanzania. Hum Resour Health. 2010;8:30

8. Tavrow P, Rukyalekere AK, Maganda A, Ndeezi G, Sebina-Zziwa A, Knebel EL. A comparison of computer-based and standard training in the integrated management of childhood illness in Uganda. 2002. https://www.usaidassist. org/sites/assist/files/uganda_computer_vs._std_training_in_imci.pdf Accessed 28 June 2018.

9. Wenger E, McDermott R, Snyder W. Cultivating communities of practice: a guide to managing knowledge. Harvard Business Review. 2002.

10. Forsetlund $L$, et al, Continuing education meetings and workshops: effects on professional practice and health care outcomes. 2009: Cochrane Database of Systematic Reviews. Apr 15:2. https://hbr.org/product/ 
cultivating-communities-of-practice-a-guide-to-managing-knowledge/an/ 3308-HBK-ENG .

11. Petros $M$, Rugare $M$. The dynamics and impact of social media on university teaching and learning: a case study of a university in Zimbabwe. Int J Res Econ Soc Sci. 2017;7(7):21-31.

12. Henry JV, Winters N, Lakati A, Oliver M, Geniets A, Mbae SM, et al. Enhancing the supervision of community health workers with WhatsApp mobile messaging: qualitative findings from 2 low-resource settings in Kenya. Glob Health Science and Practice. 2016;4(2):311-25.

13. Blumenfeld O, Brand R. Disaster and Military Medicine. 2016;2:12. https:// doi.org/10.1186/s40696-016-0022-7

14. Mbuagbaw L, Mursleen S, Lytvyn L, Smieja M, Dolovich L, Thabane L. Mobile phone text messaging interventions for HIV and other chronic diseases: an overview of systematic reviews and framework for evidence transfer. BMC Health Serv Res. 2015;15:33.

15. Alipour S, Moini A, Jafari-Adli S, Gharaie N, Mansouri K. Comparison of teaching about breast cancer via mobile or traditional learning methods in gynecology residents. Asian Pac J Cancer Prev. 2012;13(9):4593-5. https:// doi.org/10.7314/APJCP.2012.13.9.4593

16. Goyal A, Tanveer N, Sharma P. WhatsApp for teaching pathology postgraduates: a pilot study. J Pathol Inform. 2017;8:6.

17. Bakshi S, Bhawalkar P. Role of WhatsApp-based discussions in improving residents' knowledge of post-operative pain management: a pilot study. Korean J Anesthesiol. 2017:70(5):542

18. Jonas, et al. Healthcare workers' behaviors and personal determinants associated with providing adequate sexual and reproductive healthcare services in sub-Saharan Africa: a systematic review. BMC Pregnancy Childbirth. 2017;17:86.

19. Ministry of Health and Child Care (MOHCC), Zimbabwe. Zimbabwe Population-Based HIV Impact Assessment (ZIMPHIA) 2015-16: first report. Harare, MOHCC. 2017; http://phia.icap.columbia.edu/wp-content/uploads/ 2017/11/ZIMPHIA_First_Report_FINAL.pdf. Accessed 29 June, 2018.

20. Bandason T, et al. Burden of HIV among primary school children and feasibility of primary school-linked HIV testing in Harare, Zimbabwe: a mixed methods study. AIDS Care. 2013;25(12):1520

21. Ferrand $\mathrm{R}$, et al. Perception of risk of vertically acquired HIV infection and acceptability of provider-initiated testing and counseling among adolescents in Zimbabwe. Am J Public Health. 2011;101(12):2325-32.

22. Number of monthly active WhatsApp users worldwide from April 2013 to December 2017 (in millions). https://www.statista.com/statistics/260819/ number-of-monthly-active-whatsapp-users/ Accessed 4 May 2018.

23. Guidelines for Antiretroviral Therapy for the Prevention and Treatment of HIV in Zimbabwe. 2016; https://aidsfree.usaid.gov/sites/default/files/Zw_arv_ therapy_prevention.pdf. Accessed 30 June 2018.

24. Thomas D. A general inductive approach for analyzing qualitative evaluation data. Am J Eval. 2006;27:237-46.

25. USAID Assist Project. (2013). A global improvement framework for health worker in-service training guidance for improved effectiveness, efficiency and sustainability. https://www.usaidassist.org/sites/assist/files/ inservicetraining_july2013.11x17spreads.pdf Accessed 30 June 2018

26. Pimmer C, Brühlmann F, Odetola TD, Dipeolu O, Gröhbiel U, Ajuwon A. Instant messaging and nursing students' clinical learning experience. Nurse Educ Today. 2018;64:119-24.

Ready to submit your research? Choose BMC and benefit from:

- fast, convenient online submission

- thorough peer review by experienced researchers in your field

- rapid publication on acceptance

- support for research data, including large and complex data types

- gold Open Access which fosters wider collaboration and increased citations

- maximum visibility for your research: over $100 \mathrm{M}$ website views per year

At BMC, research is always in progress.

Learn more biomedcentral.com/submissions 